\title{
Evaluation of Prescription Pattern and its Economic Losses at Sudan National Medical Supplies
}

\section{Mohamed TE ${ }^{1}$ and Awad $\mathrm{MM}^{2 *}$ \\ ${ }^{1}$ Health Economic Center, University of Khartoum, Sudan \\ ${ }^{2}$ Department of Pharmacy Practice, International University of Africa, Sudan}

*Corresponding author: Mousand Mohamed Awad, Department of Pharmacy Practice, Faculty of Pharmacy, International University of Africa, Khartoum, Sudan, Tel: 00249912325864; Email: m_abdalaziz@yahoo.com

\section{Research Article \\ Volume 2 Issue 2}

Received Date: March 25, 2019

Published Date: April 09, 2019

DOI: $10.23880 /$ jqhe- 16000118

\section{Abstract}

Rational: Studies conducted showed that there were gaps regarding the rational use of medicines (RUM).

Aims and Objectives: to evaluate of prescriptions pattern and its economic losses at National Medical Supplies Fund (NMSF) Khartoum pharmacy, using WHO indicators.

Method: A cross-sectional study was conducted using random sampling method, a total of 100 prescriptions were collected and analyzed from May- July 2016. Index of Rational Drug Prescribing (IRDP), dispensing, health facility and complementary indicators were selected and used as an indicator of RUM.

Main Results: the mean values of prescribing indicators of RUM were estimated to be within the WHO optimal values for number of drugs per prescription (2.5 Vs >3) and antibiotics (5\% vs. $>30 \%$ ), However, the discrepancy was reported regarding the injections indicator which was found to be more than the WHO optimal value (31\% vs. >10\%) and generics to be less than the WHO optimal value (30\% vs. $100 \%)$.The economic loss due to irrational use of injections was high $(85 \%)$.

Conclusions: Strategies and interventions are desirable to promote RUM and minimize the consequences of using injectable medicines.

Keywords: Health Care; Polypharmacy; Immunology; Health Insurance

Abbreviations: RUM; Rational use of Medicines; NMSF: National Medical Supplies Fund; IRDP: Index of Rational Drug Prescribing; WHO: World Health Organization; GDP: Gross Domestic Product.

\section{Introduction}

Medicines play an essential role in health care delivery and disease prevention. The availability and affordability of good quality drugs along with their rational use is needed for effective health care [1].

World Health Organization (WHO)estimates that globally "more than half of all medicines are prescribed, dispensed, or sold inappropriately and that half of all patients fail to take their medicines correctly" Both healthcare providers and patients contribute to irrational medicine use [2]. Essential medicines are those that 


\section{Journal of Quality in Health Care \& Economics}

satisfy the priority health care needs of the population [3] About one-third of the world's population lacks access to essential medicines [4]. The irrational use may take the form of overuse, underuse and misuse of prescription or non-prescription medicines. Polypharmacy, overuse of antibiotics, overuse of injections, wrong medicines, and under use of available effective medicines are examples of irrational drug use [5-9].

There are many factors contributed to irrational use of medicines and they classified into four dimensions: Health system, prescriber, dispenser and patient and community [10-14]. The impact of irrational drug use includes antimicrobial resistance which has an increasingly significant threat to global public health, adverse drug reactions and medication errors, lost resources which between $10-40 \%$ of national health budgets are spent on medicines, and eroded patient confidence which exacerbated by the overuse of limited medicines, drugs may be often out of stock or at unaffordable prices and as result erode patient confidence [15-17].

\section{Health and Pharmaceutical Expenditures}

The health demands for all countries are increasing as a result of population growth, disease patterns reflecting the illnesses of both under development and industrialization, the occurrence of new diseases such as Ebola, and the emergence of new technologies. Yet, in efforts to reduce debt and stabilize economies, several countries have limited public funding for health. As a result, those who most need basic health services are increasingly unable to meet their needs. Ministries of health must focus the momentum for change on developing mechanisms to meet such needs, and they must do so by involving both the public and private sectors [18].

Health expenditures average about 5\% of Gross Domestic Product (GDP) across all developing countries and that reflect the lower public health spending (the lower share of health in national budget). Spending on drug related directly to GDP although the variation in the percentage of spending on drug not different significantly between developed and developing countries, $0.8 \%$ and $0.79 \%$ respectively [19].

Irrational use of medicines is a major challenge facing many health systems across the world. Such practices are likely to lead to poor health delivery that may put patients at risk and result in wastage of scarce resources that could have been used to tackle other pressing health needs [20]. The pharmaceutical management aim to deliver the correct, proper and appropriate use of medicines to patient.

\section{Health Insurance and Rational use of Medicines}

To ensure equitable financing, affordability and delivery of essential medicines with a focus on promoting establishment of sustainable ways of financing medicines expenditure through health insurance schemes. Also promoting therapeutically sound and cost-effective use of medicines by health workers and consumers with a focus on efforts to increase rational use of medicines among prescribers and consumers through working with health insurance systems to promote the use of essential medicines [21].

\section{Interventions to Control Rational use of Medicines}

To address irrational use of medicines, prescribing, dispensing and patient use should be regularly monitored in terms of: the types of irrational use, so that strategies can be targeted towards changing specific problems; the amount of irrational use, so that the size of the problem is known and the impact of the strategies can be monitored; the reasons why medicines are used irrationally, so that appropriate, effective and feasible strategies can be chosen. People often have very rational reasons for using medicines irrationally. Causes of irrational use include lack of knowledge, skills or independent information, unrestricted availability of medicines, overwork of health personnel, inappropriate promotion of medicines and profit motives from selling medicines [4].

In 1997, the International Conference on Improving the Use of Medicines in Chiang Mai, Thailand was the first global scientific conference purely devoted to strategies for improving drug use in developing countries [12].

\section{Rational Use of Medicines in Sudan}

In Sudan, according to 2003 estimates, there were 5,944 Physicians, 244 Dentists, 674 pharmacists and 17,174 Nurses employed by the Ministry of Health. Half the physicians are located in the three largest cities in Khartoum State. With respect to physical resources, there were 1,864 primary health care units, 951 health centers and 453 hospitals. The total number of community pharmacies in Sudan is 2,940. 622 of them which represent $21.2 \%$ are located in Khartoum State that included three cities: Khartoum 275, Omdurman219, Khartoum North 128, while the number of pharmacists is 3,900 , approximately $60 \%$ of whom are in Khartoum 


\section{Journal of Quality in Health Care \& Economics}

State. The literature show that essential elements of prescription were missing in both Khartoum and Omdurman hospitals in up to $91 \%$ of the records reviewed [22].

\section{National Medical Supplies Fund}

National Medical Supplies Fund (NMSF) is the national center for procurement, storage and distribution of medical supplies in Sudan. The range of medical supplies at NMSF includes medicines, vaccines and other biologicals, medical consumables and a wide range of medical equipment. These supplies are provided to public health facilities and the private sector in addition to many other organizations. The pharmaceutical procurement system is a major determinant of pharmaceutical availability and total pharmaceutical costs. In most developing countries, pharmaceutical purchases represent the single largest health expenditure after personnel costs. An effective procurement process helps ensure the availability of the right medicines in the right quantities, at reasonable prices, and at recognized standards of quality. A country can acquire pharmaceuticals through purchase, donation, or local manufacture. Quantification is an important step in the procurement process that involves estimating not only the quantities needed of a specific item, but also the financial means required for purchasing the item. The primary goal is to maintain a steady supply of pharmaceuticals and supplies to facilities where they are needed, while ensuring that resources are being used in the most effective way. The distribution cycle begins when pharmaceuticals are dispatched by the manufacturer or supplier. It ends when medicine consumption information is reported back to the procurement unit. Designing systems for distributing and storing medicines, supplies, and equipment is complex and important.

Current research aims to evaluate medicines prescription pattern and its economic losses at NMSF pharmacies in Khartoum, Sudan.

\section{Materials and Methods}

Cross-sectional study was conducted at NMSF Khartoum pharmacy that consider as the most crowded pharmacy using random sampling method and considering the pharmacy as health facility, a total of 100 prescriptionswere collected. The sample size was in accordance with WHO recommendation for practice assessment in individual facilities which requires that a minimum of 100 samples per facility should be collected for the purpose of evaluation [23]. A standard WHO prescribing indicators form was used to collect the required variables. This study was conducted capital of Sudan at NMSF Khartoum pharmacy that located in Khartoum locality in May- July2016.

\section{Study Instrument and Tools}

According to the WHO definition of rational use of medicines to determine the independent variables that lead to irrational use of medicines the following conceptual frame work was developed [24]. The framework recognizes the need to take various perspectives individual, community development and public health in planning, implementing and evaluating initiatives to improve use of medicines.

Prescribing Indicators Measure: average number of medicines per encounter, percentage of medicines prescribed by generic name, Percentage of encounters with an antibiotic prescribed and Percentage of encounters with an injection prescribed.

Patient Care Indicators Measure: average dispensing time, Percentage of medicines actually dispensed and percentage of medicines adequately labelled.

Health Facility Indicators: availability of a copy of essential medicines list or formulary.

Complementary Medicine-Use Indicators: measure average pharmaceutical cost per encounter, percentage of pharmaceutical costs spent on antibiotics, percentage of pharmaceutical costs spent on injections.

\section{Data Collection Procedure and Data Analysis}

Three well-trained pharmacist collected data on both prescribing and dispensing indicators prospectively from pharmacy. Data were collected using questionnaires for patients filled by the interviewer. Data collection from the pharmacies followed the WHO guidelines and methodology to ensure reliability of data collection. Data collected by designed questionnaires from WHO indicators which included Core medicine-use indicators and Complementary medicine-use indicators. Sets of data obtained from samples will be collected. Data entry and analysis were conducted using Microsoft office excel 2007 Descriptive statistics were used in the form of mean. 


\section{Results}

Prescribing Indicators Measure

\begin{tabular}{|c|c|c|}
\hline Indicator & Result & $\begin{array}{c}\text { Optimal } \\
\text { value }\end{array}$ \\
\hline $\begin{array}{c}\text { Average no. of medicines per } \\
\text { encounter Rx }\end{array}$ & 2.5 & $<3$ \\
\hline $\begin{array}{c}\text { Percentage of medicines prescribed } \\
\text { by generic name (INN) }\end{array}$ & $30 \%$ & $100 \%$ \\
\hline $\begin{array}{c}\text { Percentage of encounter with } \\
\text { antibiotics prescribed }\end{array}$ & $5 \%$ & $<30 \%$ \\
\hline $\begin{array}{c}\text { Percentage of encounter with } \\
\text { injection prescribed }\end{array}$ & $31 \%$ & $<10 \%$ \\
\hline
\end{tabular}

Table 1: Prescribing indicators.

Patient Care Indicators Measure

\begin{tabular}{|c|c|c|}
\hline Indicator & Result & $\begin{array}{c}\text { Optimal } \\
\text { value }\end{array}$ \\
\hline Average dispensing time - min & 6.6 & $* *$ \\
\hline $\begin{array}{c}\text { Percentage of Medicines actually } \\
\text { dispensed }\end{array}$ & $54 \%$ & $100 \%$ \\
\hline $\begin{array}{c}\text { Percentage of Medicines } \\
\text { adequately labeled }\end{array}$ & $44 \%$ & $100 \%$ \\
\hline
\end{tabular}

Table 2: Patient care indicators.

\section{Health Facility Indicators}

\begin{tabular}{|c|c|c|}
\hline Indicator & Result & Optimal value \\
\hline $\begin{array}{c}\text { Availability of a copy of } \\
\text { essential medicines list }\end{array}$ & $100 \%$ & $100 \%$ \\
\hline
\end{tabular}

Table 3: Health facility indicators.

\section{Complementary Medicine-Use Indicators}

\begin{tabular}{|c|c|}
\hline Indicator & Result \\
\hline $\begin{array}{c}\text { Average pharmaceutical cost per } \\
\text { encounter (direct cost) }\end{array}$ & $665.6 \mathrm{SDG}$ \\
\hline $\begin{array}{c}\text { Average pharmaceutical cost(direct } \\
\text { and in direct) per encounter }\end{array}$ & $686.6 \mathrm{SDG}$ \\
\hline $\begin{array}{c}\text { Percentage of pharmaceutical costs } \\
\text { spent on injections }\end{array}$ & $85 \%$ \\
\hline $\begin{array}{c}\text { Percent of household income is spent } \\
\text { on purchasing medicine }\end{array}$ & $18.50 \%$ \\
\hline $\begin{array}{c}\text { Percentage of expenditures of } \\
\text { transportation cost to pharmaceutical } \\
\text { cost }\end{array}$ & $3.10 \%$ \\
\hline
\end{tabular}

Table 4: Complementary medicine-use indicators.

\section{Discussion}

The main finding of the present study was that, the mean values of prescribing indicators of RUM at NMSF Khartoum pharmacy was estimated to be within the WHO optimal values for number of medicines per prescription and Percentage of encounter with antibiotics prescribed (Table 5). However, the discrepancy was reported regarding percentage of medicines prescribed by generic name (INN) and Percentage of encounter with injection prescribed which were found to be more than the WHO optimal value.

This study compared WHO prescribing indicators from the present study with other studies conducted in Sudan, UAE, Saudi Arabia [25-27].

\begin{tabular}{|c|c|c|c|c|c|c|c|}
\hline \multicolumn{1}{|c|}{ Study } & Year & $\begin{array}{c}\text { Number of } \\
\text { healthcare } \\
\text { facilities }\end{array}$ & $\begin{array}{c}\text { Number of } \\
\text { prescriptions }\end{array}$ & $\begin{array}{c}\text { Average } \\
\text { number of } \\
\text { drugs per } \\
\text { encounter (N) }\end{array}$ & $\begin{array}{c}\text { Generic } \\
\text { prescribing } \\
\text { Percentage } \\
\text { (\%) }\end{array}$ & $\begin{array}{c}\text { Antibiotic } \\
\text { prescribing } \\
\text { (\%) }\end{array}$ & $\begin{array}{c}\text { Injection } \\
\text { prescribing } \\
\text { (\%) }\end{array}$ \\
\hline Present study & 2016 & 1 pharmacy & 100 & 2.5 & 30 & 5 & 31 \\
\hline Sudan & 2006 & $\begin{array}{c}\text { 2teaching hospital } \\
\text { (Referral) }\end{array}$ & 200 & 2.1 & 46.2 & 59 & 12 \\
\hline UAE & 2012 & $\begin{array}{c}\text { 4hospital } \\
\text { (specialized) }\end{array}$ & 1100 & 2.49 & 100 & 9.8 & 3.14 \\
\hline Saudi Arabia & 1991 & $\begin{array}{c}\text { 1teaching hospital } \\
\text { (PHC) }\end{array}$ & 500 & 1.69 & 43.2 & 15.6 & 1.8 \\
\hline
\end{tabular}

Table 5: WHO prescribing indicators.

Comparison of WHO prescribing indicators between this study and other studies. Study; Year Number of health care facilities (hospitals); Number of prescriptions
WHO prescribing indicators average number of drugs per encounter( $\mathrm{N})$; Generic prescribing percentage (\%) Antibiotic prescribing (\%); Injection prescribing (\%). All 


\section{Journal of Quality in Health Care \& Economics}

the studies show that the indexes of poly-pharmacy were within the range of WHO optimal value.

In UAE the overall index of generic prescribing was optimal in all the hospitals due to the use of the electronic prescribing system which was termed Wareed in Arabic indicating life-supply). The average percentage of generic prescribing in hospitals in UAE in the present study was equal to the WHO optimal value $(100 \%)$. Lower results were reported from studies conducted in Sudan (present study $30 \%$ and previous study $46 \%$ ) and KSA (43.2\%). The importance of implementation of electronic prescribing systems was apparent in maintaining generic prescribing in healthcare facilities where all the medicines are entered to the system with their generic name. This enables patient to choose between alternatives available and not to be limited to the brand drug. This indicated the importance of raising the awareness of the prescribers toward this issue and to encourage them to prescribe the medicines by their generic names even if the facility does not implement an electronic prescribing system. NMSF introduce electronic system to all state in Sudan to order all medicines in the generic name to introduce the awareness of prescribing generic name in supply chain.

The index of rational antibiotic prescribing was optimal. Higher result was reported from other study in Sudan (59\%). Antibiotic prescribing in the hospitals was lower in all the Emirates and Saudi Arabia.

The percentage of injection prescribing in the present study was (31\%) higher than the WHO optimal value. Similar results were obtained from previous study in Sudan $(12 \%)$. Very low results were reported from UAE $(3 \%)$ and KSA $(1.8 \%)$. It is important to raise the awareness of prescribers and to encourage them to continuously improve their prescribing of injections according to the guidelines set by $\mathrm{WHO}$ and give preference to the oral route whenever possible; especially when the patient is able to take the drug orally. This is particularly important to improve patient adherence, reduce the cost and save the resources since the injection preparations are more expensive than the oral dosage forms.

Regarding Patient care indicator there is no optimal value for average dispensing time but when compared with other study (25) the average dispensing time in this study (6.6 $\mathrm{min}$ ) is more than that in Khartoum teaching hospital (0.85) and Omdurman teaching hospital (0.69) Medicines actually dispensed. More dispensing time may indicate more information about medicines for patient especially almost patient that haunt NMSF Khartoum pharmacy are outpatient.

Regarding Dispensing indicators medicines actually dispensed in this study was (54\%) while Khartoum teaching hospital (86.5\%) and Omdurman teaching hospital (83.9\%).

To measure the economic impact, other standard indicators were used that reflect the cost of the medication, the amounts paid by the patient and compared with income of households, as the study measured the economic losses (economic loss) resulting from the irrational use of medication.

The Average pharmaceutical cost per encounter (direct cost) was 665.6 SDG and Average pharmaceutical cost (direct and indirect) per encounter was 686.6.The transportation cost consider as indirect cost and not measure for who used their private car. Percentage of expenditures of transportation cost to pharmaceutical cost (3.1\%). As result of percentage of encounter with injection prescribed was high (31\%) also percentage of pharmaceutical costs spent on injections was high (85\%) of total spending on prescription.

\section{Conclusions}

Strategies and interventions are desirable to promote RUM and minimize the consequences of using injectable medicines. The prescriber practice regarding no. of medicines per encounter and percentage of antibiotics per encounter are good.

Regulations must be activated to promote generic prescribing. The study has revealed inadequate skills in dispensing regarding labelling of medicines. From economic point of view irrational use of medicines considered as financial burden to household.

\section{Limitations of the Study}

The absence of study that calculate the economic impact of irrational use of medicines with all dimensions that include consequence on health system, patient and community.

\section{Contribution of the Findings}

The choice of interventions to control irrational drug use depends on the type and magnitude of drug use problem and the reasons why it exists. 


\section{Journal of Quality in Health Care \& Economics}

This paper estimate the economic impact of irrational drug use at National Medical Supplies Fund, Sudan and identified interventions which should be apply for future. Calculation of economic cost (financial cost added to opportunity cost) rather than calculation of financial cost only. Strategies and interventions are desirable to promote RUM and minimize the consequences of using injectable medicines. More studies at different health facilities level have to conduct to determine the interventions that are cost- effective.

\section{References}

1. WHO (1985) The Rational use of drugs: report of the conference of experts, Nairobi, World Health Organization pp: 1-338.

2. Zelman W (2015) Promoting the Rational Use of Medicines, pp: 1-8.

3. Hogerzeil HV (2004) The concept of essential medicines: lessons for rich countries. BMJ 329(7475): 1169-1172.

4. WHO (2002) Promoting rational use of medicines: core components, pp: 1-16.

5. Montamat SC, Cusack B (1992) Overcoming problems with polypharmacy and drug misuse in the elderly. Clin geriatr med 8(1): 143-158.

6. Goossens H, Ferech M, Vander Stichele R, Elseviers M, Group EP (2005) Outpatient antibiotic use in Europe and association with resistance: a cross-national database study. The Lancet 365(9459): 579-587.

7. Talaat M, El-Oun S, Kandeel A, Abu-Rabei W, Bodenschatz C, et al. (2003) Overview of injection practices in two governorates in Egypt. Trop Med Int Health 8(3): 234-241.

8. WHO (2010) WHO Medicines: rational use of medicines. Fact sheet no 338.

9. Cheekavolu C, Pathapati RM, Babasaheb Laxmansingh K, Saginela SK, Makineedi VP, et al. (2011) Evaluation of drug utilization patterns during initial treatment in the emergency room: a retro prospective pharmacoepidemiological study. ISRN pharmacol 2011: 261585.

10. Bratzler DW, Dellinger EP, Olsen KM, Perl TM, Auwaerter PG, et al. (2013) Clinical practice guidelines for antimicrobial prophylaxis in surgery. Am J health syst phar 70(3): 195-283.

11. Quick JD, Laing RO, Ross-Degnan DG (1991) Intervention research to promote clinically effective and economically efficient use of pharmaceuticals: the International Network for Rational Use of Drugs. J clinl epidemiol 45(S2): S57-S65.

12. Laing R, Hogerzeil H, Ross-Degnan D (2001) Ten recommendations to improve use of medicines in developing countries. Health policy and planning 16(1): 13-20.

13. Kamat VR, Nichter M (1998) Pharmacies, selfmedication and pharmaceutical marketing in Bombay, India. Soc Sci Med 47(6): 779-794.

14. Çelik E, Şencan Mn, Clark MP (2013) Factors Affecting Rational Drug Use (Rdu), Compliance and Wastage. Turkish Journal of Pharmaceutical Sciences 10(1): 151-169.

15. Pirmohamed M, Breckenridge AM, Kitteringham NR, Park BK (1998) Adverse drug reactions. British Medical Journal 316(7140): 1295.

16. Kar SS, Pradhan HS, Mohanta GP (2010) Concept of essential medicines and rational use in public health. Indian J Community med 35(1): 10-13.

17. Desalegn AA (2013) Assessment of drug use pattern using WHO prescribing indicators at Hawassa University teaching and referral hospital, south Ethiopia: a cross-sectional study. BMC health services research 13(1): 170.

18. Madrid Y, Velásquez G, Fefer E (1998) The economics of pharmaceuticals and health sector reform in the Americas. Revista Panamericana de Salud Pública 3(5): 343-350.

19. WHO (2000) Global Comparative Pharmaceutical Expenditures with Related Reference InformationHealth Economics and Drugs Series No. 003 2000(3): 84.

20. Ofori-Asenso R, Agyeman AA (2016) Irrational Use of Medicines A Summary of Key Concepts. Pharmacy 4(4): 35 .

21. Strategy WM (2004) WHO Medical Strategy-Countries at the core. 


\section{Journal of Quality in Health Care \& Economics}

22. Awad AI, Eltayeb IB, Capps PA (2006) Self-medication practices in Khartoum state, Sudan. Eur J clin pharmacol 62(4): 317-324.

23. Quick JD, Hogerzeil HV, Velásquez G, Rägo L (2002) Twenty-five years of essential medicines. Bull World Health Organ 80(11): 913-914.

24. Mao W, Vu H, Xie Z, Chen W, Tang S (2015) Systematic review on irrational use of medicines in China and Vietnam. PloS one 10(3): e0117710.
25. Awad AI, Himad HA (2006) Drug-use practices in teaching hospitals of Khartoum State, Sudan. Eur $\mathrm{j}$ clinl pharmacol 62(12): 1087-1093.

26. Mahmood A, Elnour AA, Ali AAA, Hassan NA, Shehab A, et al. (2016) Evaluation of rational use of medicines (RUM) in four government hospitals in UAE. Saudi Pharm J 24(2): 189-196.

27. Kasim AD (1995) Evaluation of drug prescribing habits in a postgraduate teaching set-up in Saudi Arabia. J Family community med 2(1): 41-46. 